\title{
ANALISIS FINANSIAL USAHA KERAJINAN KALIGRAFI KULIT KAMBING DI KECAMATAN SUKOHARJO KABUPATEN SUKOHARJO
}

\author{
Shanti Emawati ${ }^{1)}$, Endang Siti Rahayu ${ }^{2)}$, Sutrisno Hadi Purnomo ${ }^{3)}$, Ayu Intan Sari ${ }^{4)}$ \\ Endang Tri Rahayu", Winny Swastike ${ }^{\text {() }}$ \\ ${ }^{133) 4556)}$ Program Studi Peternakan, Fakultas Pertanian, Universitas Sebelas Maret \\ ${ }^{2)}$ Program Studi Agribisnis, Fakultas Pertanian, Universitas Sebelas Maret \\ E-mail : shanti_uns@yahoo.co.id
}

\begin{abstract}
The research was conducted to determine the feasibility of financial on SMEs calligraphy goat leather in Sukoharjo District. Research was done from January 6 to March 26, 2015 in located in Sukoharjo District. Survey methods was done to collect primary data from respondents and secondary data from related institution. Census method was applied to sellect respondents. Criteria used to analyze the feasibility of financial on SMEs calligraphy goat leather were consisted of Benefit Cost Ratio (BCR), Net Present Value (NPV), Internal Rate of Return (IRR) and Payback Period (PPC), based on 6 years investment and 12\% annual discount factor. The result showed that based on NPV, IRR, BCR and payback period analysis, the most feasible of respondents was achieved on scale of 3 with value of $N P V=R p$. $434,852,752.00, I R R=37.93 \%, B C R=1.92$, followed by on scale of 2 with value of $N P V=R p .76,481,554.00, I R R=22.51 \%, B C R=1.37$ and on scale of 1 with value of $N P V=R p .34,883,505.00, I R R=20.41 \%$ dan $B C R=1.28$. In term of payback period, respondents who had SMEs calligraphy goat leather on scale of 3 were able to return the investment during 2.39 years while on scale of 2 and on scale of 1 were 3.72 and 3.79 years, respectively.
\end{abstract}

Keywords : SMEs calligraphy, goat leather, financial analysis, feasibility

\begin{abstract}
Abstrak: Tujuan dari penelitian ini adalah menganalisis kelayakan usaha kerajinan kaligrafi kulit kambing di Kabupaten Sukoharjo. Penelitian ini dilaksanakan di Kabupaten Sukoharjo pada tanggal 6 Januari-26 Maret 2015. Metode penelitian yang digunakan adalah survei untuk mengumpulkan data primer dari responden dan data sekunder dari dinas terkait. Responden diambil secara purposive sampling. Analisis kelayakan finansial usaha kerajinan kaligrafi kulit kambing menggunakan kriteria investasi benefit cost ratio (BCR), net present value (NPV), internal rate of return (IRR) dan payback period (PPC) berdasarkan umur investasi 6 tahun dengan discount factor 12\%/tahun. Hasil analisis menunjukkan bahwa usaha kerajinan kaligrafi kulit kambing layak dijalankan dengan nilai kelayakan terbaik adalah pada skala 3 dengan nilai $\mathrm{NPV}=\mathrm{Rp} .434 .852 .752,00, \mathrm{IRR}=37,93 \%, \mathrm{BCR}=1,92$, kemudian usaha kerajinan pada skala 2 dengan nilai $\mathrm{NPV}=\mathrm{Rp} .76 .481 .554,00, \mathrm{IRR}=22,51 \%, \mathrm{BCR}=$ 1,37 selanjutnya usaha kerajinan pada skala 1 dengan nilai NPV $=$ Rp. 34.883.505,00, $\mathrm{IRR}=20,41 \%$ dan $\mathrm{BCR}=1,28$. Nilai payback period usaha kerajinan kaligrafi kulit kambing di Kecamatan Sukoharjo Kabupaten Sukoharjo pada skala 3, skala 2 dan skala 1 berturut-turut adalah 2,39 tahun, 3,72 tahun dan 3,79 tahun.
\end{abstract}

Kata Kunci: usaha kerajinan kaligrafi, kulit kambing, analisis finansial, kelayakan

\section{PENDAHULUAN}

Pengembangan industri kecil harus difokuskan pada sub sektor-sub sektor yang menjadi andalan dan sektor yang menjadi unggulan. Kuncoro dan Widjajanto (2001) mengartikan potensi sektor andalan sebagai potensi dari sektor yang dimiliki secara dominan tanpa 
mempertimbangkan kemampuan daya saing sektor tersebut dalam perekonomian, sedangkan potensi subsektor unggulan adalah potensi subsektor andalan yang memiliki kemampuan daya saing (competitive advantages).

Menurut Arto dan Hutomo (2013), tantangan atau kecenderungan yang paling besar yang dihadapi dalam membangun koperasi, usaha mikro, kecil dan menengah (KUMKM) sehingga tangguh dan memiliki daya saing tinggi ke depan adalah globalisasi, demokratisasi, dan desentralisasi/ otonomisasi, serta menghindari terjadinya krisis pangan, energi dan dampak resesi dunia menjalar ke perekonomian nasional. Posisi dan kondisi UMKM termasuk usaha kerajinan kaligrafi kulit kambing di Kabupaten Sukoharjo membutuhkan berbagai dukungan dalam pengembangannya.

Peningkatan produktivitas UMKM ini tentu diperlukan dalam rangka mengatasi ketimpangan antar pelaku, antar golongan pendapatan dan antar daerah, termasuk dalam rangka penanggulangan kemiskinan, selain sekaligus mendorong peningkatan daya saing nasional. Pada sisi lain, UMKM juga memiliki keterbatasan kemampuan untuk akses kepada sumberdaya produktif, terutama terhadap permodalan, teknologi, informasi dan pasar. Dalam hal pendanaan, produk jasa lembaga keuangan sebagian besar masih berupa kredit modal kerja, sedangkan kredit investasi masih sangat terbatas. Bagi UMKM, keadaan ini sulit untuk meningkatkan kapasitas usaha ataupun mengembangkan produk-produk yang mampu bersaing di pasar. Berdasarkan latar belakang tersebut penting dilakukannya penelitian mengenai analisis finansial usaha kerajinan kaligrafi kulit kambing di Kabupaten Sukoharjo untuk mengetahui kelayakan usaha yang dijalankan.

\section{METODE PENELITIAN}

Penelitian dilaksanakan 6 Januari-26 Maret 2015 dengan lokasi di Kabupaten Sukoharjo. Jumlah responden yang diambil sebagai sampel penelitian adalah 30 orang. Metode penelitian yang digunakan adalah survei untuk mengumpulkan data primer dari responden dan data sekunder dari dinas terkait. Metode penentuan lokasi penelitian dan pengambilan sampel ditentukan secara sengaja, dengan pertimbangan di Kabupaten Sukoharjo terdapat pengrajin kaligrafi kulit kambing yang tergabung dalam KUB Pandawa. Pemilihan secara purposive berarti sampel dipilih dan ditetapkan berdasarkan pertimbanganpertimbangan tertentu yang sesuai dengan tujuan penelitian (Sugiyono, 2006).

\section{Analisis Data}

\section{Analisis kriteria kelayakan}

1. Benefit cost ratio (BCR). Rumus yang digunakan :

$$
\mathrm{BCR}=\frac{\text { Discounted gross benefit }}{\text { Discounted total cost }}
$$

(Gittinger, 1986)

Suatu usaha apabila nilai net $\mathrm{B} / \mathrm{C}$ ratio $>1$, maka usaha layak dijalankan, sedangkan untuk nilai net $\mathrm{B} / \mathrm{C}$ ratio $<1$, maka proyek tidak layak dijalankan (Prawirokusumo, 1990).

2. Net present value (NPV). Rumus yang digunakan :

$$
\mathrm{NPV}=\sum_{\mathrm{t}=1}^{\mathrm{n}} \frac{\mathrm{Bt}-\mathrm{Ct}}{(1+\mathrm{i})^{\mathrm{t}}}
$$

Keterangan :

$$
\begin{aligned}
\mathrm{B}_{\mathrm{t}}= & \text { Benefit } / \text { keuntungan kotor yang } \\
& \text { diperoleh pada tahun } \mathrm{t} \\
\mathrm{C}_{\mathrm{t}}= & \begin{array}{l}
\text { Cost } / \text { biaya yang dikeluarkan pada } \\
\text { tahun } \mathrm{t}
\end{array} \\
\mathrm{i}= & \text { tingkat diskonto } \\
\mathrm{n}= & \text { umur ekonomi proyek (tahun) }
\end{aligned}
$$

Suatu proyek apabila nilai NPV > 0 , maka proyek tersebut layak dijalankan. Jika $\mathrm{NPV}=0$, berarti proyek tersebut mengembalikan persis sebesar social opportunity cost of capital. Jika NPV $<0$, proyek supaya ditolak artinya adanya penggunaan lain yang lebih menguntungkan untuk sumber-sumber yang diperlukan proyek (Kadariah et al., 1999).

3. Internal rate of return (IRR). Rumus yang digunakan : 
Shanti E., Endang S.R., Sutrisno H.P., Ayu I. S., Endang T.R., Winny S. : Analisis Finansial ...

$$
I R R=i^{\prime}+\frac{N P V^{\prime}}{N P V^{\prime}+N P V^{\prime}} X\left(i^{\prime \prime}-i^{\prime}\right)
$$

(Soekartawi, 2006)

Keterangan :

$$
\begin{aligned}
\mathrm{NPV}^{\prime}= & \text { NPV yang positif } \\
\mathrm{NPV} "= & \text { NPV yang negatif } \\
\mathrm{i}= & \text { tingkat bunga yang menghasilkan } \\
& \text { NPV positif } \\
\mathrm{i} " \quad & \text { tingkat bunga yang menghasilkan } \\
& \text { NPV negatif }
\end{aligned}
$$

Suatu usaha apabila nilai IRR > social discount rate, maka usaha tersebut akan layak dan apabila nilai IRR < social discount rate, maka proyek tersebut tidak akan layak (Pudjosumartono, 1995).

4. Payback period. Rumus yang digunakan :

$$
\text { Payback period }=\frac{\text { Investasi }}{\text { Net benefit rata-rata tiap tahun }}
$$

(Choliq et al., 1999)

\section{Batasan Operasional}

1. Responden yang diambil sebagai sampel penelitian adalah pengrajin yang berlokasi di Kecamatan Sukoharjo Kabupaten Sukoharjo yang memiliki usaha kerajinan kaligrafi kulit kambing minimal telah berjalan 1 tahun

2. Perhitungan analisis finansial ditetapkan dalam jangka waktu selama 6 tahun dengan menggunakan dasar perhitungan proyeksi dari data-data penelitian

3. Perhitungan analisis kelayakan usaha dilakukan dengan penggunaan tingkat bunga (discount rate) 12\% sesuai dengan tingkat bunga yang berlaku

4. Nilai yang dimasukkan dalam cash flow hanya merupakan nilai tunai yang ada

5. Penerimaan dan pendapatan usaha kerajinan kaligrafi kulit kambing dinyatakan dalam skala usaha ( $\mathrm{Rp} /$ tahun) sebagai berikut
a. Skala I : $\leq$ Rp 12.000.000,00 - Rp 36.000.000,00
b. Skala II : Rp 36.001.000,00 - Rp 60.000.000,00
c. Skala III $: \geq \operatorname{Rp} 60.001 .000,00$

\section{HASIL DAN PEMBAHASAN}

\section{Karakteristik Responden Umur responden}

Umur responden adalah berkisar antara 41-60 tahun dengan jumlah responden sebanyak 25 orang atau sebesar $83,33 \%$. Umur responden kerajinan kaligrafi kulit kambing dapat dilihat pada Tabel 1.

Tabel 1. Umur responden kerajinan kaligrafi kulit kambing di Kecamatan Sukoharjo

\begin{tabular}{ccc}
\hline $\begin{array}{c}\text { Umur } \\
\text { (tahun) }\end{array}$ & $\begin{array}{c}\text { Jumlah } \\
(\text { Orang) }\end{array}$ & Persentase (\%) \\
\hline$\leq 20$ & 0 & 0 \\
$21-40$ & 2 & 6,67 \\
$41-60$ & 25 & 83,33 \\
$>60$ & 3 & 10,00 \\
\hline
\end{tabular}

Sumber: Data primer terolah, 2015

Umur responden tergolong usia produktif. Menurut Arsyad (1999), umur produktif adalah umur antara 15 tahun sampai dengan 60 tahun, sedang umur dibawah 15 tahun dan lebih dari 60 tahun termasuk dalam umur non produktif. Menurut Setiana (2000), pada umur produktif mempunyai kondisi fisik, tindakan, serta kemampuan berfikir seseorang yang masih baik. Umur produktif manusia mempunyai kemampuan untuk berpikir kreatif dan dapat menambah daya kerja dalam meningkatkan produktivitas sehingga potensi umur akan mempengaruhi kelangsungan suatu usaha (Dewi, 2016).

\section{Jenis kelamin}

Pengrajin kaligrafi kulit kambing di Kabupaten Sukoharjo rata-rata berjenis kelamin laki-laki sebanyak 29 orang atau sebesar 96,67\%. Jenis kelamin responden kerajinan kaligrafi kulit kambing dapat dilihat pada Tabel 2.

Tabel 2. Jenis kelamin responden kerajinan kaligrafi kulit kambing di Kecamatan Sukoharjo, Kabupaten Sukoharjo

\begin{tabular}{ccc}
\hline $\begin{array}{c}\text { Jenis } \\
\text { kelamin }\end{array}$ & $\begin{array}{c}\text { Jumlah } \\
\text { (orang) }\end{array}$ & Persentase (\%) \\
\hline Laki-laki & 29 & 96,67 \\
Perempuan & 1 & 3,33 \\
\hline Jumlah & 30 & 100
\end{tabular}

Sumber: Data primer terolah, 2015. 
Pengrajin kaligrafi membutuhkan kondisi fisik yang bagus dalam menjalankan usaha sehingga sebagian besar pengrajin berjenis kelamin laki-laki dan bertindak sebagai keluarga kepala keluarga dalam mencari nafkah (Noviana, 2016). Menurut Marmawi (2009), laki-laki bertanggung jawab sebagai pemimpin keluarga, pencari nafkah utama dan bertanggung jawab atas kelangsungan hidup anak dan istrinya.

\section{Tingkat Pendidikan Responden}

Tingkat pendidikan formal responden rata-rata hanya tamatan SD sebanyak 11 orang atau sebesar $36,67 \%$. Tingkat pendidikan responden kerajinan kaligrafi kulit kambing dapat dilihat pada Tabel 3.

Tabel 3. Tingkat pendidikan responden kerajinan kaligrafi kulit kambing di Kecamatan Sukoharjo, Kabupaten Sukoharjo

\begin{tabular}{lcc}
\hline $\begin{array}{c}\text { Tingkat } \\
\text { pendidikan }\end{array}$ & $\begin{array}{c}\text { Jumlah } \\
\text { (orang) }\end{array}$ & Persentase (\%) \\
\hline Tidak sekolah & 1 & 3,33 \\
SD & 11 & 36,67 \\
SMP & 8 & 26,67 \\
SMA & 10 & 33,33 \\
\hline \multicolumn{1}{c}{ Jumlah } & 30 & 100
\end{tabular}

Sumber: Data primer terolah, 2015.

Hal tersebut menunjukkan bahwa tingkat pendidikan pengrajin tergolong rendah. Tingkat pendidikan pengrajin berpengaruh terhadap manajemen usaha kerajinan kaligrafi kulit kambing yang dilakukan. Pendidikan pengrajin menggambarkan kemampuan mengelola usaha kerajinan kaligrafi. Pendidikan dipandang tidak hanya meningkatkan keahlian dan ketrampilan, melainkan juga dapat memperbaiki sikap dan menambah pengetahuan sumber daya manusia, yang pada akhirnya dapat meningkatkan produktivitas (Sutawi, 2007).

\section{Pengalaman Responden}

Pengalaman pengrajin rata-rata lebih dari 20 tahun sebanyak 11 orang atau sebesar $36,67 \%$. Pengalaman pengrajin kaligrafi kulit kambing dapat dilihat pada Tabel 4.
Tabel 4. Pengalaman pengrajin kaligrafi kulit kambing di Kecamatan Sukoharjo, Kabupaten Sukoharjo

\begin{tabular}{ccc}
\hline $\begin{array}{c}\text { Lama } \\
\text { (tahun) }\end{array}$ & $\begin{array}{c}\text { Jumlah } \\
\text { (orang) }\end{array}$ & Persentase (\%) \\
\hline$<10$ & 10 & 33,33 \\
$10-20$ & 9 & 30 \\
$>20$ & 11 & 36,67 \\
\hline Jumlah & 30 & 100 \\
\hline
\end{tabular}

Sumber: Data primer terolah, 2015.

Semakin lama menjalankan usaha kerajinan kaligrafi menunjukkan lama pengalaman yang dimiliki pengrajin. Pengalaman kerja memiliki pengaruh positif terhadap produktivitas tenaga kerja (Adhadika, 2013).

\section{Jumlah Anggota Keluarga}

Jumlah anggota keluarga usaha kerajinan kaligrafi kulit kambing dengan kisaran 3-5 orang rata-rata sebanyak 24 orang atau sebesar $80 \%$. Jumlah anggota keluarga responden usaha kaligrafi kulit kambing dapat dilihat pada Tabel 5.

Semakin besar jumlah anggota keluarga menunjukkan ketersediaan jumlah tenaga kerja. Nurcahya (2009) mengatakan bahwa keluarga yang relatif banyak merupakan sumber persediaan tenaga kerja, tetapi juga merupakan beban hidup yang harus ditanggung dan dinafkahi oleh kepala keluarga tersebut.

Tabel 5. Jumlah anggota keluarga responden usaha kerajinan kaligrafi kulit kambing Kecamatan Sukoharjo Kabupaten Sukoharjo

\begin{tabular}{ccc}
\hline $\begin{array}{c}\text { Jumlah anggota } \\
\text { keluarga (orang) }\end{array}$ & $\begin{array}{c}\text { Jumlah } \\
\text { (keluarga) }\end{array}$ & $\begin{array}{c}\text { Persentase } \\
(\%)\end{array}$ \\
\hline$<3$ & 0 & 0 \\
$3-5$ & 24 & 80 \\
$>5$ & 6 & 20 \\
\hline Jumlah & 30 & 100
\end{tabular}

Sumber: Data primer terolah, 2015.

\section{Pelatihan yang Diikuti Responden}

Jumlah pengrajin yang telah mengikuti pelatihan sebanyak 21 orang atau sebesar $70 \%$. Jumlah pelatihan yang diikuti responden 
kerajinan kaligrafi kulit kambing dapat dilihat pada Tabel 6.

Tabel 6. Pelatihan yang diikuti pengrajin kaligrafi kulit kambing di Kecamatan Sukoharjo Kabupaten Sukoharjo

\begin{tabular}{lcc}
\hline Pengalaman & $\begin{array}{l}\text { Jumlah } \\
\text { (orang) }\end{array}$ & Persentase (\%) \\
\hline Terlatih & 21 & 70 \\
Tidak Terlatih & 9 & 30 \\
\hline Jumlah & 30 & 100 \\
\hline
\end{tabular}

Sumber: Data primer terolah, 2015.

Pelatihan yang pernah diikuti oleh pengrajin kaligrafi ini antara lain pelatihan penyamaan kulit dan juga pelatihan pemasaran, cara peminjaman, pembukuan, managemen, komunikasi, mutu dan kualitas, kerajinan dan perindustrianSemakin banyak pelatihan yang diikuti pengrajin maka semakin meningkat ketrampilan yang dimiliki pengrajin. Hal ini sesuai dengan pendapat Arep dan Tanjung (2002) bahwa pelatihan merupakan salah satu usaha untuk mengembangkan Sumber Daya Manusia (SDM), terutama dalam hal pengetahuan (knowledge), kemampuan (ability), keahlian (skill), dan sikap (attitude).

\section{Aspek Finansial Usaha Kerajinan Kaligrafi Kulit Kambing}

\section{Analisis cash flow}

Analisis cash flow memperhitungkan nilai aliran penerimaan uang tunai dan non tunai yang dinilai uangkan dengan opportunity cost (input cash flow) serta aliran biaya yang semua dinilai uangkan (outflow cash flow). Berdasarkan hasil penelitian, nilai cumulatif net cash flow untuk usaha kerajinan kaligrafi kulit kambing cukup tinggi. Hal ini disebabkan tingginya nilai penjualan kerajinan kaligrafi dalam berbagai ukuran, yaitu yang ukuran kecil $(36 \times 46 \mathrm{~cm})$, ukuran sedang $(38 \times 48 \mathrm{~cm})$, maupun besar ukuran besar $(50 \times 70 \mathrm{~cm})$. Sebagian besar permintaan kerajinan Kaligrafi dari luar negeri dengan ukuran yang lebih kecil yaitu $25 \times 25 \mathrm{~cm}$. Pengrajin kaligrafi kulit kambing di Kecamatan Sukoharjo, Kabupaten Sukoharjo rata-rata dapat memproduksi kerajinan kaligrafi sebanyak 1000 buah kaligrafi ukuran kecil dengan harga $\mathrm{Rp}$ 18.000,00, sebanyak 800 buah kaligrafi ukuran sedang dengan harga Rp 26.000,00 dan 600 buah kaligrafi ukuran besar dengan harga $\mathrm{Rp}$ 42.000,00 (Taufik, 2016).

Semakin besar nilai cumulatif net cash flow yang diperoleh menunjukkan bahwa usaha kerajinan kaligrafi yang dijalankan pengrajin mendapatkan keuntungan. Namun perhitungan tersebut belum dapat digunakan sebagai indikator kelayakan usaha karena belum di discount factor. Hasil tersebut hanya menunjukkan bahwa pada periode usaha tertentu telah dicapai hasil yang positif. Oleh karena itu perlu dilakukan analisis investasi yang memperhitungkan nilai uang di masa mendatang dengan menggunakan discount factor. Perhitungan cash flow dibuat dalam jangka waktu 6 tahun dapat dilihat pada Lampiran 1.

\section{Analisis finansial usaha kerajinan kaligrafi kulit kambing}

Analisis finansial untuk menilai kelayakan usaha kerajinan kaligrafi penting dilakukan karena untuk mengetahui apakah usaha yang dijalankan tersebut dalam jangka waktu tertentu dapat mendatangkan keuntungan atau tidak bagi peternak. Kelayakan usaha yang dijalankan menggunakan tiga kriteria uji kelayakan yaitu NPV, IRR dan BCR dengan menggunakan discount rate $12 \%$ dan jangka waktu investasi 5 tahun. Besarnya nilai kriteria finansial usaha kerajinan kaligrafi kulit kambing di Kecamatan Sukoharjo Kabupaten Sukoharjo dapat dilihat pada Tabel 7.

Tabel 7. Kriteria finansial usaha kerajinan kaligrafi kulit kambing di Kecamatan Sukoharjo Kabupaten Sukoharjo

\begin{tabular}{llll}
\hline \multirow{2}{*}{$\begin{array}{c}\text { Kriteria } \\
\text { finansial }\end{array}$} & \multicolumn{3}{c}{ Nilai kriteria finansial } \\
\cline { 2 - 4 } NPV & Skala 1 & Skala 2 & Skala 3 \\
BCR & 34.883 .5 & Rp. & Rp. \\
IRR & 05,00 &, 00 & $2,001.554$ \\
Payback & 1,28 & 1,37 & 1,92 \\
period & $20,41 \%$ & $22,51 \%$ & $37,93 \%$ \\
& 3,79 & 3,72 tahun & 2,39 tahun \\
& tahun & & \\
\hline
\end{tabular}

Sumber : Data primer terolah, 2016

Berdasarkan Tabel 7 terlihat bahwa usaha kerajinan kaligrafi kulit kambing di Kecamatan Sukoharjo, Kabupaten Sukoharjo tersebut layak untuk dijalankan karena NPV 
bernilai positif, $\mathrm{BCR}>1$ dan IRR > discount factor. Perhitungan NPV, BCR dan IRR dapat dilihat pada Lampiran 2.

Kriteria NPV. Analisis NPV penting dilakukan karena sejumlah uang tertentu pada saat sekarang mempunyai nilai berbeda dimasa mendatang. NPV merupakan seluruh angka net cash flow yang digandakan dengan discount factor pada tahun dan tingkat bunga yang telah ditentukan (Soekartawi, 2006). Suatu usaha dikatakan layak untuk dijalankan apabila NPV bernilai positif (Kadariah, 1999).

Penelitian ini menggunakan discount factor $12 \%$ berdasarkan tingkat suku bunga yang berlaku saat penelitian. Berdasarkan hasil penelitian menunjukkan bahwa nilai NPV pada pada ketiga skala tersebut memiliki nilai positif sehingga layak dijalankan. Nilai NPV usaha kerajinan kaligrafi kulit kambing di Kecamatan Sukoharjo Kabupaten Sukoharjo pada skala 3 lebih besar daripada skala 2 dan skala 1 dengan nilai sebesar Rp. 434.852.752,00.

Kriteria BCR. BCR merupakan perbandingan antara hasil antara hasil yang dipresent-valuekan dengan biaya modal sebagai indikator bisa diterima atau tidaknya suatu investasi yang dijalankan. Suatu usaha dikatakan layak dijalankan apabila nilai BCR > 1 (Kadariah et al., 1999).

Berdasarkan hasil penelitian, nilai BCR pada ketiga skala tersebut bernilai lebih dari satu. Hal ini berarti NPV usaha kerajinan kaligrafi kulit kambing di Kecamatan Sukoharjo Kabupaten Sukoharjo layak dijalankan karena penerimaan yang diperoleh peternak lebih besar daripada biaya yang dikeluarkan. Usaha kerajinan kaligrafi kulit kambing pada skala 3 nilai BCR yang diperoleh lebih besar dibandingkan pada skala 1 dan skala 2 sebesar 1,92 sehingga diantara ketiga skala tersebut tersebut, usaha kerajinan kaligrafi kulit kambing di Kecamatan Sukoharjo Kabupaten Sukoharjo yang paling layak untuk dijalankan adalah pada skala 3.

Kriteria IRR. IRR merupakan tingkat keuntungan bersih atas investasi karena benefit bersih yang positif ditanam kembali dalam tahun berikutnya dan mendapatkan tingkat bunga yang sama selama sisa umur proyek (Soekartawi, 2006). Suatu usaha layak dijalankan apabila nilai IRR lebih besar dari tingkat bunga (discount rate) yang berlaku pada saat penelitian (Kadariah, 1999).
Hasil penelitian menunjukkan bahwa pada ketiga skala tersebut memiliki nilai IRR lebih besar dari $12 \%$. Hal ini berarti produsen mampu mengembalikan investasi yang ditanamkan. Nilai IRR pada skala 3 lebih besar dibandingkan pada skala 2 dan skala 1 yaitu sebesar $37,93 \%$ sehingga diantara ketiga skala tersebut, usaha kerajinan kaligrafi kulit kambing di Kecamatan Sukoharjo Kabupaten Sukoharjo pada skala 3 paling layak untuk dijalankan.

Payback period. Payback period menunjukkan jangka waktu yang diperlukan untuk mengembalikan seluruh modal yang digunakan pada investasi awal. Nilai payback period tersebut apabila lebih pendek dari umur investasi, maka usaha tersebut menguntungkan sehingga layak untuk dijalankan, namun apabila payback period tersebut lebih panjang dari umur investasi maka usaha tersebut tidak layak dijalankan (Husnan dan Suwarsono, 2005).

Berdasarkan penelitian diperoleh bahwa nilai payback period pada skala 3 lebih pendek dibandingkan pada skala 1 dan skala 2 yaitu sebesar 2,39 tahun. Hal ini berarti dalam kurun waktu kurang dari tiga tahun dapat mengembalikan investasi sehingga usaha kerajinan kaligrafi kulit kambing di Kecamatan Sukoharjo Kabupaten Sukoharjo pada skala 3 paling baik dijalankan karena paling cepat mengembalikan investasi dibandingkan pada skala 1 dan skala 2. Menurut Cholig et al. (1999), semakin cepat waktu pengembalian maka semakin baik untuk diusahakan.

\section{KESIMPULAN}

Berdasarkan analisis finansial usaha kerajinan kaligrafi kulit kambing di Kecamatan Sukoharjo Kabupaten Sukoharjo dengan menggunakan umur investasi 6 tahun, discount factor $12 \%$, menghasilkan nilai kelayakan paling bagus adalah pada skala 3 dengan nilai $\mathrm{NPV}=$ Rp. 434.852.752,00, IRR $=37,93 \%$, $\mathrm{BCR}=1,92$, kemudian usaha kerajinan pada skala 2 dengan nilai NPV $=$ Rp. 76.481.554,00, $\mathrm{IRR}=22,51 \%, \mathrm{BCR}=1,37$ selanjutnya usaha kerajinan pada skala 1 dengan nilai $\mathrm{NPV}=\mathrm{Rp}$. $34.883 .505,00, \mathrm{IRR}=20,41 \%$ dan $\mathrm{BCR}=1,28$. Nilai payback period usaha kerajinan kaligrafi kulit kambing di Kecamatan Sukoharjo Kabupaten Sukoharjo pada skala 3, skala 2 dan 
skala 1 berturut-turut adalah 2,39 tahun, 3,72 tahun dan 3,79 tahun.

\section{DAFTAR PUSTAKA}

Adhadika, T. 2013. Analisis Faktor-Faktor yang Mempengaruhi Produktivitas Tenaga Kerja Industri Pengolahan di Kota Semarang. Fakultas Ekonomi dan Bisnis Universitas Diponegoro. Semarang.

Arep, I. dan H. Tanjung. 2002. Manajemen Sumber Daya Manusia. Universitas Trisakti. Jakarta.

Arsyad. 1999. Ekonomi Pembangunan. Sekolah Tinggi Ilmu EkonomiYayasan Keluarga Pahlawan Negara (YKPN). Yogyakarta.

Arto, A. dan B.S. Hutomo. 2013. "Enam Pilar Insektisida" Kebijakan Pengembangan Dan Penguatan Umkm Berbasis Kerjasama Kemitraan Dengan Pola CSR Sebagai Strategi Peningkatan Peran Pemerintah Dan Perusahaan Untuk Menjaga Eksistensi UMKM Dalam MEA 2015. Economics Development Analysis Journal. 2 (2) (2013). Hal 97109.

Choliq, A., H.R.A.Wirasasmita dan S. Hasan. 1999. Evaluasi Proyek, Suatu Pengantar. Pioner Jaya. Bandung.

Dewi, P.S. 2016. Kontribusi Usaha Mikro Kecil Menengah (Umkm) Kaligrafi Kulit Kambing Terhadap Pendapatan Produsen Di Kecamatan Sukoharjo Kabupaten Sukoharjo. Skripsi. Fakultas Pertanian. Universitas Sebelas Maret. Surakarta

Husnan, S. dan Suwarsono. 2005. Studi Kelayakan Proyek. Fakultas Ekonomi. Universitas Gadjah Mada. Yogyakarta.

Gittinger, J.P. 1986. Analisa Ekonomi ProyekProyek Pertanian. UI-Press. Jakarta.

Kadariah, L. Karlina dan C. Gray. 1999. Pengantar Evaluasi Proyek. Fakultas Ekonomi. Universitas Indonesia, Jakarta.
Kuncoro, M. dan K. Widjajanto. 2001. Analisis Profil dan Masalah Industri Kecil dan Rumah Tangga : Studi Kasus di Kabupaten Ngawi, Jawa Timur. Jurnal Ekonomi Pembangunan. Vol.6 No. 1 : 33.

Marmawi. 2009. Persamaan Gender dalam Pengembangan Diri. Jurnal Visi Ilmu Pendidikan No. 1 Vol. 2. Universitas Tanjungpura. Tanjungpura.

Noviana, D. 2016. Faktor-Faktor Yang Mempengaruhi Keputusan Penggunaan Internet Pada Pengrajin Kaligrafi Kulit Kambing Di Kecamatan Sukoharjo Kabupaten Sukoharjo. Skripsi. Fakultas Pertanian. Universitas Sebelas Maret. Surakarta.

Nurcahya, Y. 2009. Rapat Kerja Perencanaan Pengembangan Hortikultura 2009. Direktorat Jenderal Hortiklutura Departemen Pertanian Kabupaten Sukoharjo. Jawa Tengah.

Prawirokusumo, S. 1990. Ilmu Usaha Tani. Edisi I. BPFE. Yogyakarta.

Pudjosumartono, M. 1995. Evaluasi Proyek, Uraian Singkat dan Soal Jawab. Liberty. Yogyakarta.

Setiana. L. 2000. Teknik Penyuluhan dan Pemberdayaan Masyarakat. Ghalia Indonesia. Bogor.

Soekartawi. 2006. Analisis Usahatani. UIPress. Jakarta.

Sugiyono. 2006. Metode Penelitian Bisnis. Cetakan 9. CV Alfabeta. Bandung.

Sutawi. 2007. Kapita Selekta Agribisnis Peternakan. Cetakan 1. UMM Press. Malang

Taufik, I. 2016. Faktor-Faktor Yang Mempengaruhi Pendapatan Usaha Kerajinan Kaligrafi Kulit Kambing Di Kecamatan Sukoharjo Kabupaten Sukoharjo. Skripsi. Fakultas Pertanian. Universitas Sebelas Maret. Surakarta. 


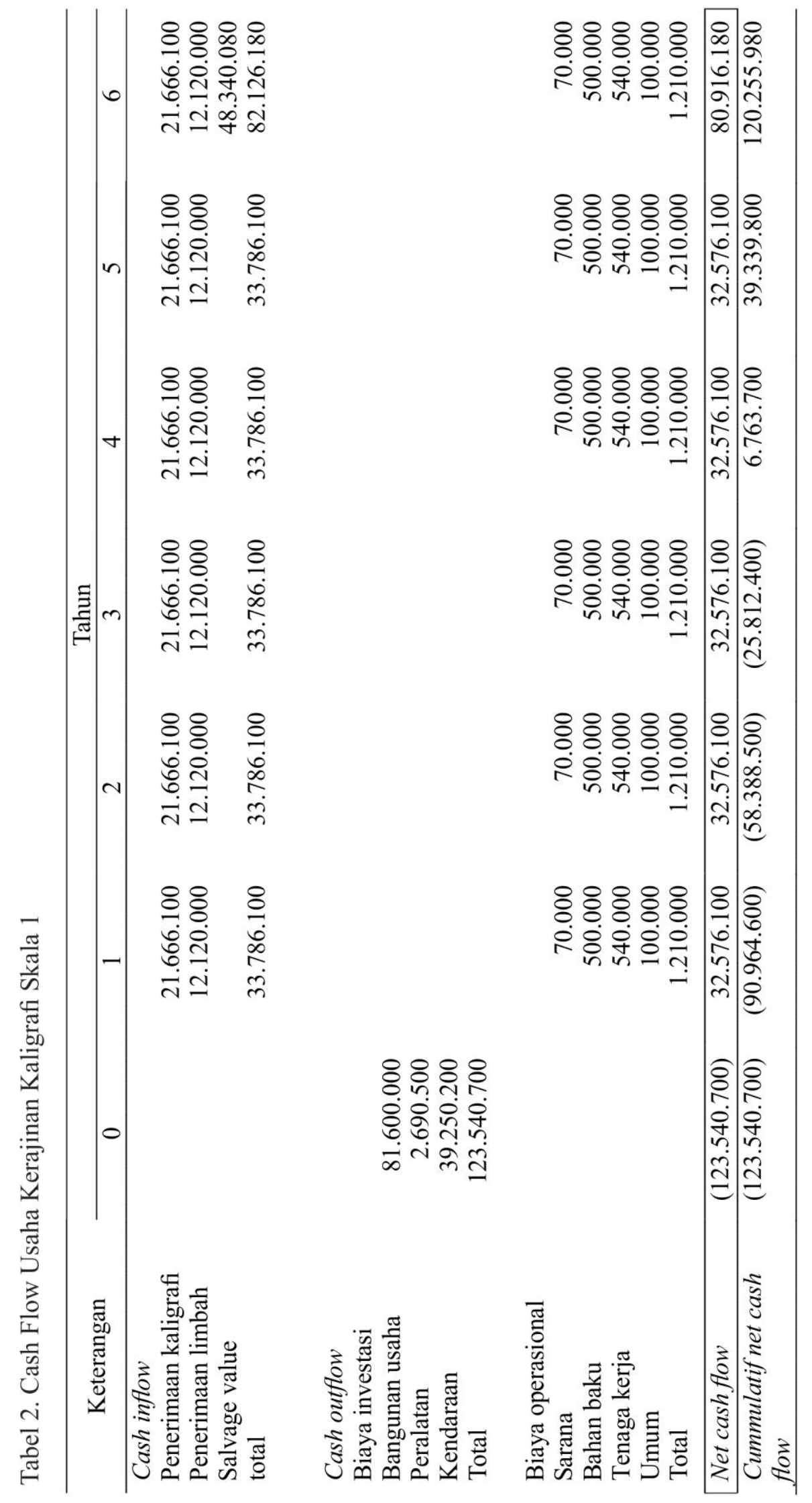




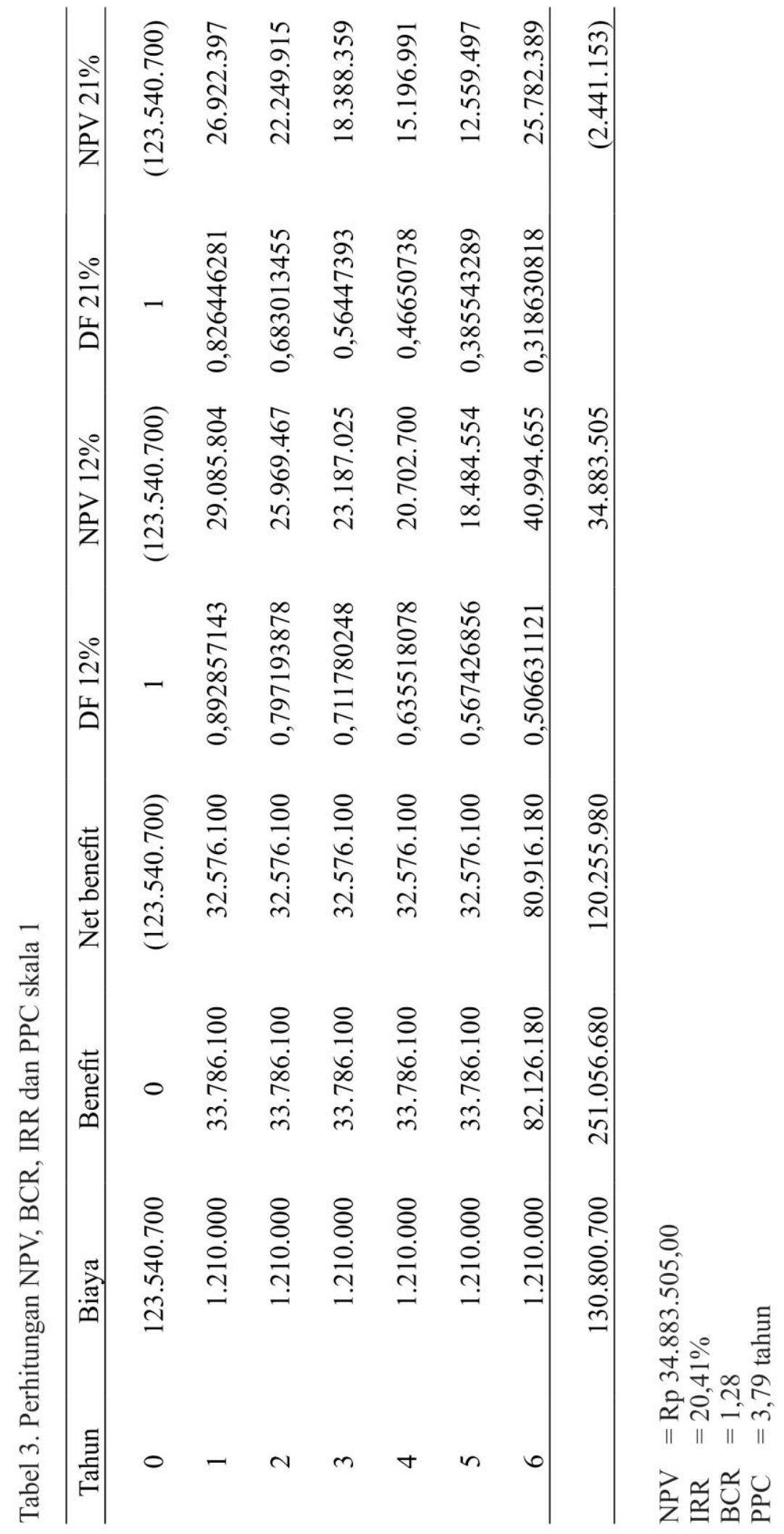




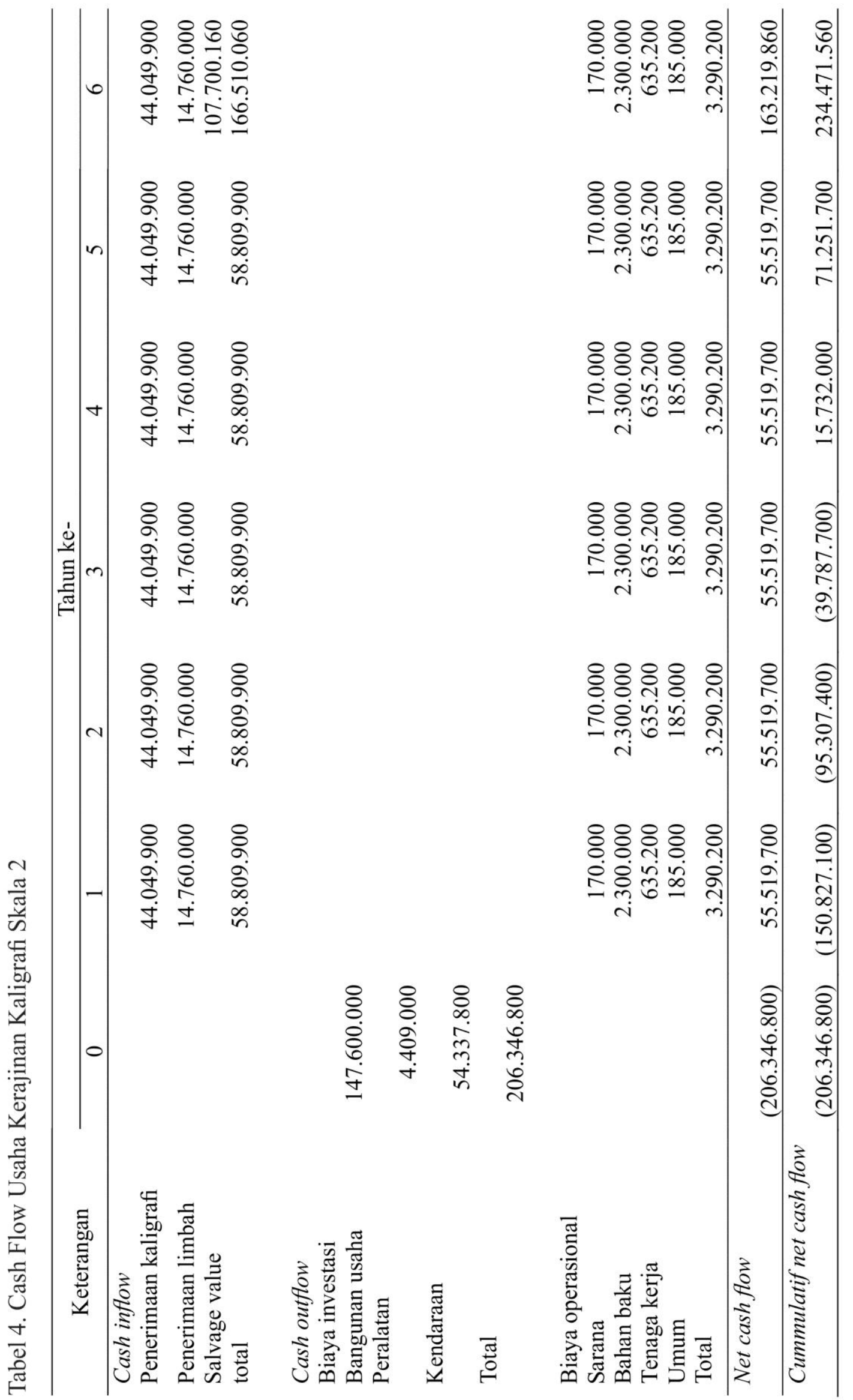




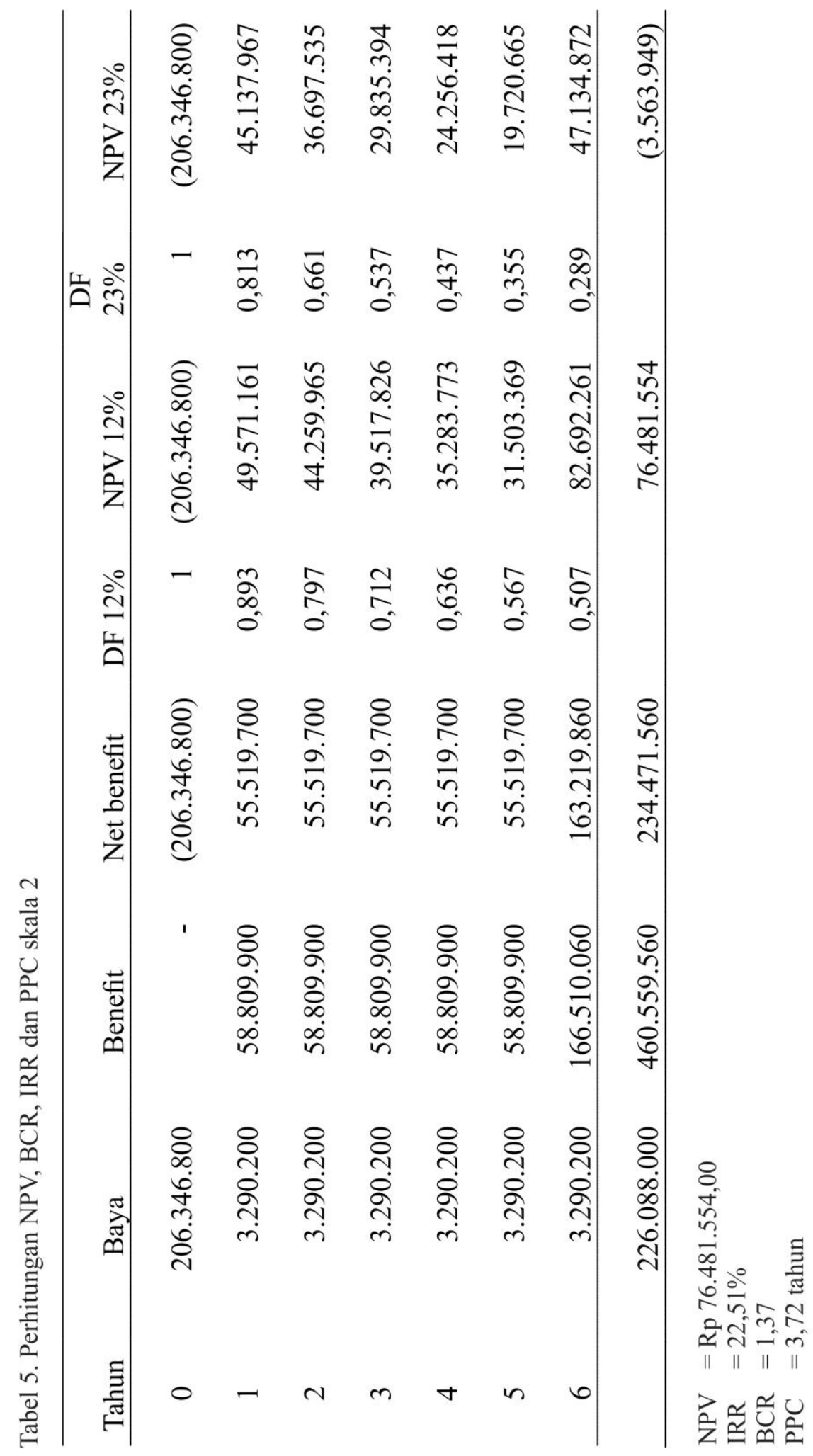




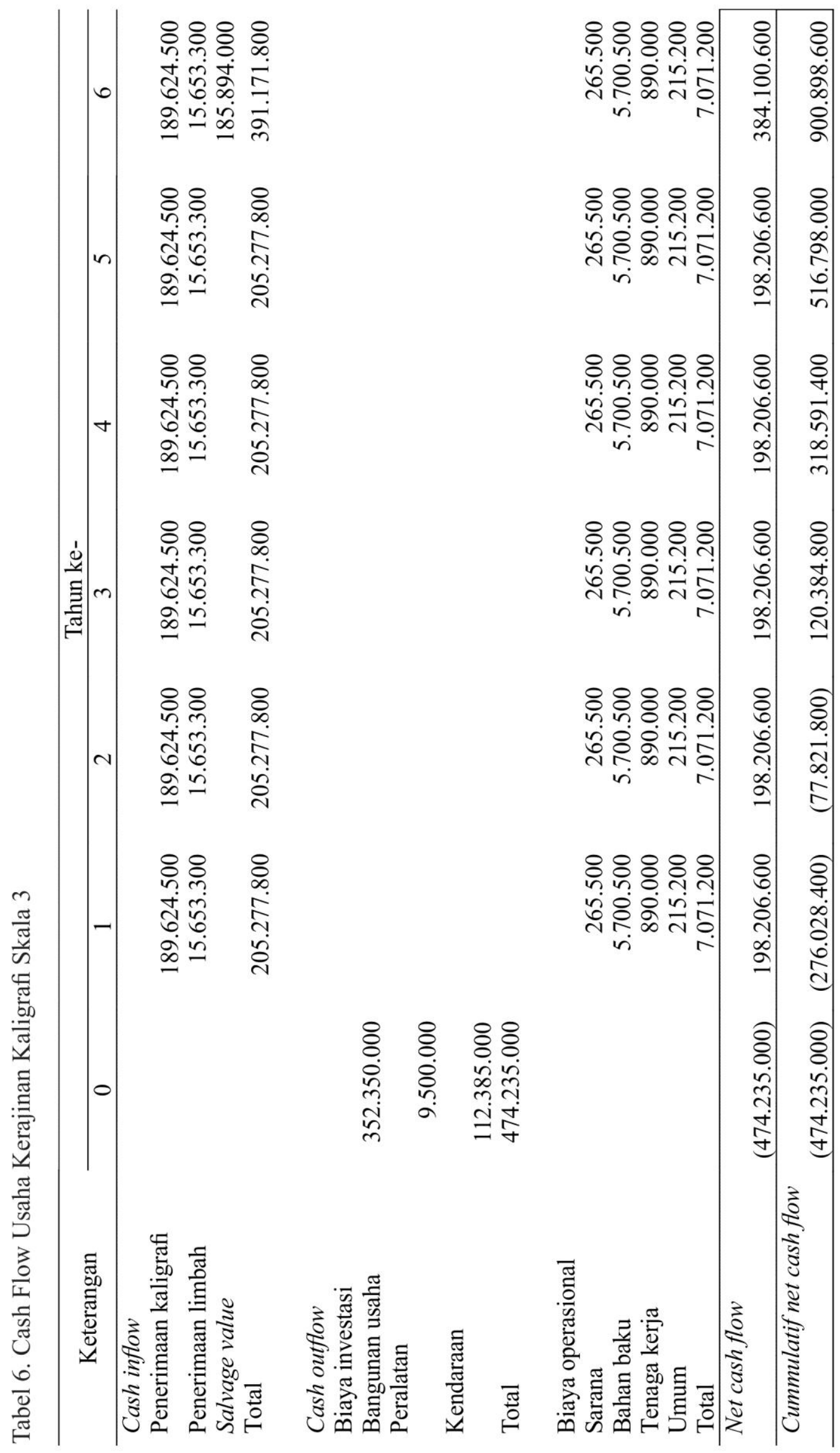




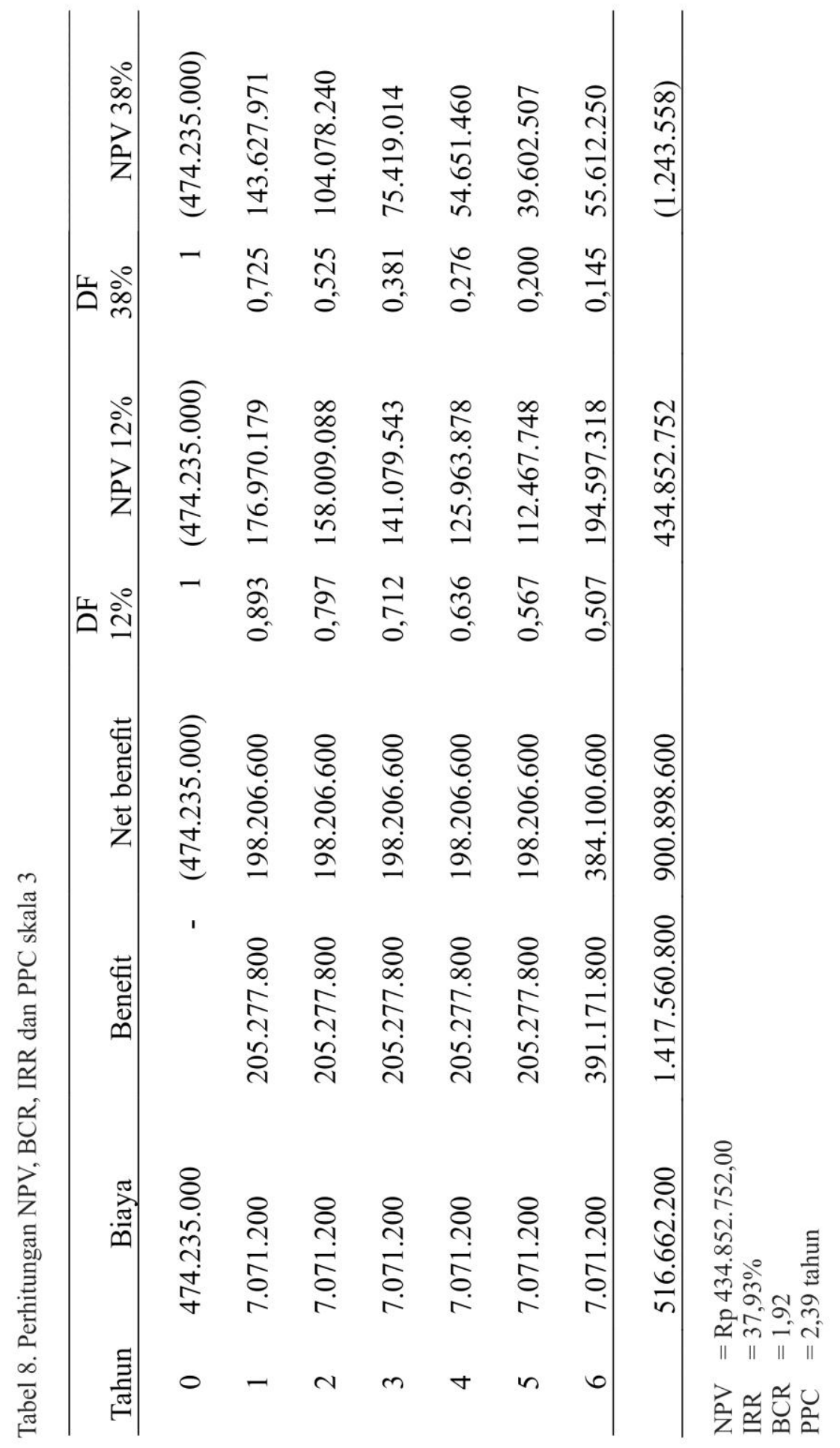

